\title{
Development of ovarian diseases in dairy cows with a history of fatty liver, and their prognosis
}

\author{
Kouichi TANEMURA ${ }^{1)}$, Tadatoshi OHTAKI ${ }^{1) *}$, Mamiko $\mathrm{ONO}^{1)}$ and Shigehisa TSUMAGARI ${ }^{1)}$ \\ ${ }^{1)}$ Laboratory of Theriogenology, College of Bioresouce Sciences, Nihon University, 1866 Kameino, Fujisawa, Kanagawa 252-0880, \\ Japan
}

(Received 3 December 2014/Accepted 28 December 2015/Published online in J-STAGE 16 January 2016)

ABSTRACT. In the present report, the incidence and prognosis of ovarian diseases were evaluated in correlation to the grades of the fatty livers (FL). 233 animals were diagnosed with a FL, based on fat deposition of $>10 \%$ into the hepatic parenchyma obtained from liver biopsy, and were eventually cured of the FL. These 233 animals were classified into mild group ( $\mathrm{n}=99$ : hepatic fat deposition rates ranging from 10 to $<30 \%$ ), moderate group $(\mathrm{n}=56$ : hepatic fat deposition rates ranging from 30 to $<60 \%)$ and severe group $(\mathrm{n}=78$ : hepatic fat deposition rates of $>60 \%$ ). The incidence of ovarian diseases and the culling rate were, respectively, $40.0 \%$ and $10.0 \%$ in mild group, $58.3 \%$ and $37.5 \%$ in moderate group, and $84.9 \%$ and $69.7 \%$ in severe group. The incidence of ovarian diseases and the culling rates in severe group were significantly $(P<0.05)$ higher than those in mild and moderate groups. It was, therefore, concluded that the elevated incidence of ovarian disease and culling rates tend to be dependent on the higher severity scores of the fat deposition rates in dairy cows with FL and that cases with severe FL, with a fat deposition rate of $60 \%$ or higher, were greatly associated with death and culling. KEY WORDS: dairy cow, fatty liver, ketosis, ovarian disease, secondary disease

doi: 10.1292/jvms.14-0637; J. Vet. Med. Sci. 78(5): 755-760, 2016

The energy intake from feed cannot keep up with that required for milk production, causing a negative energy balance (NEB), especially due to a rapid increase in the milk yield after delivery. This is the reason for the recent reduction in the reproductive performance of dairy cows. In a perinatal NEB state, the liver triglyceride (TG) and blood free fatty acid (NEFA) levels increase $[19,26]$ to compensate for the insufficient energy by degrading the fat accumulated in adipose tissues and mobilizing it to the liver. However, excess fat mobilization is likely to lead to a fatty liver (FL) and reduction of the liver function $[14,15]$.

FL frequently develops in dairy cows after calving. Clinically, it accompanies ketosis in many cases, often leading to anorexia. It is also closely involved in other perinatal diseases and markedly reduces subsequent milk production. The incidence of intractable perinatal diseases induced by FL is high in high-yielding and obese cows $[18,36,39]$. Based on the amount of fat deposited, the condition of the liver can be categorized as normal (mild), moderate or severe FL. The diagnosis of FL is possible only by minor surgery [2].

Insulin-like growth factor-1 (IGF-1) has been reported to be an important factor related to the first ovulation of follicles after delivery; high blood IGF-1 and insulin levels stimulate the growth and the final maturation step of the dominant follicle in the first follicular wave after delivery

\footnotetext{
*Correspondence to: Ohtaki, T., Laboratory of Theriogenology, College of Bioresource Sciences, Nihon University, 1866 Kameino, Fujisawa, Kanagawa 252-0880, Japan.

e-mail: ohtaki.tadatoshi@nihon-u.ac.jp

(C)2016 The Japanese Society of Veterinary Science

This is an open-access article distributed under the terms of the Creative Commons Attribution Non-Commercial No Derivatives (by-nc-nd) License $<$ http://creativecommons.org/licenses/by-nc-nd/4.0/>.
}

[16]. Since the IGF-1 production and secretion mainly occur in the liver, liver hypofunction may inhibit these processes and influence reproductive performance.

We investigated the influence of FL on reproduction with regard to the development and prognosis of ovarian diseases in cows with a history of FL.

\section{MATERIALS AND METHODS}

Holstein dairy cows $(n=366)$ were diagnosed with ketosis based on clinical symptoms and a positive reaction of the ketone bodies in the urine to the BM test (Astellas Pharma Inc., Tokyo, Japan). These animals were then examined for the presence of a FL and its severity by liver biopsy, for which the specimens were blindly collected using a puncture device for cattle liver (Fujihira Co., Tokyo, Japan). The puncture was made within a surgical field set at about $25 \mathrm{~cm}$ below the top-line between the right 11th and 12th costal bones [23]. These animals were divided into four groups based on the severity of the FL as follows: no-FL group $(n=133)$ had hepatic fat deposition rates of $<10 \%$; mild FL group ( $n=99$ ) had hepatic fat deposition rates ranging from 10 to $<30 \%$; moderate FL group $(n=56)$ had hepatic fat deposition rates ranging from 30 to $<60 \%$; and severe FL group $(n=78)$ had hepatic fat deposition rates of $>60 \%$ [6]. All of the cases with FLs $(n=233)$ were successfully treated by the intravenous administration of 5,000 mg/head of 2-mercaptopropinylglycine (tiopronin, Santen Pharmaceutical Co., Osaka, Japan), and the productivity of the animals returned to normal. In the present study, 99 mild FL cases, 56 moderate FL cases and 78 severe FL cases were used for statistical analyses in occurrences of ovarian diseases, and the culling or death rates. Systemic diseases, including liver disorders, mastitis, displacement of the abomasums, uterine diseases and others, 
Table 1. Case information in three severity groups of fatty livers

\begin{tabular}{lccc}
\hline & Mild $(\mathrm{n}=99)$ & Moderate $(\mathrm{n}=56)$ & Severe $(\mathrm{n}=78)$ \\
\hline Age (years) & $5.3 \pm 0.4$ & $4.8 \pm 0.4$ & $5.2 \pm 0.5$ \\
Number of parities (times) & $3.4 \pm 0.4$ & $3.4 \pm 0.4$ & $3.4 \pm 0.3$ \\
Body weight (kg) & $658.2 \pm 14.3$ & $636.2 \pm 20.2$ & $670.1 \pm 22.3$ \\
Interval between deliveries (days) & $437.4 \pm 23.7$ & $416.7 \pm 20.3$ & $455.4 \pm 21.3$ \\
Postpartum day on first onset of ketosis (days) & $9.7 \pm 2.7$ & $5.2 \pm 2.6$ & $9.2 \pm 3.0$ \\
Frequency of treatment (days) & $9.0 \pm 0.9$ & $10.5 \pm 1.2$ & $12.9 \pm 1.6$ \\
Duration of cure (days) & $11.5 \pm 1.5$ & $12.3 \pm 1.2$ & $15.9 \pm 2.0$ \\
\hline
\end{tabular}

Fatty liver has been categorized into three classes: a mild fatty liver (mild) with a fat deposition rate of $10-30 \%$; moderate fatty liver (moderate) with a fat deposition rate of $30-60 \%$; and severe fatty liver (severe) with a fat deposition rate of $60 \%$ or more.

were recorded in $49.5 \%$ (49/99) of the mild FL cases, $57.2 \%$ (32/56) of the moderate FL cases and $57.7 \%$ (45/78) of the severe FL cases. Culling or death due to systemic diseases was recorded in $53.1 \%(26 / 49)$ of the mild FL cases, $75.0 \%$ (24/32) of the moderate FL cases and $88.9 \%$ (40/45) of the severe FL cases. The final number of cases of living animals in each of the groups after the onsets of the systemic diseases was 23 mild FL cases, 8 moderate FL cases and 5 severe FL cases, respectively. In the present report, these cases were together identified as the "complications group" (C group). In addition, 50 mild FL cases, 24 moderate FL cases and 33 severe FL cases that had not developed any systemic diseases, were identified as the "non-complications group" (NC group).

The age, body weight, number of parities, interval between deliveries and first day of the exhibition of clinical signs were recorded for the animals in each of the FL groups.

The ovarian diseases were diagnosed by palpation per rectum. Ovulation failure is diagnosed by a delayed or no release of the egg from the ovarian follicle in the preovulatory period, although the animal shows a normal behavioral estrus [24]. Follicular cysts in dairy cattle are generally defined as follicular structures of at least $2.5 \mathrm{~cm}$ diameter that persist for at least 10 days in the absence of a corpus luteum [17]. Subestrus is defined by the absence of a detectable estrus cycle from the time of calving and the presence of a corpus luteum [33]. Ovarian quiescence is defined as the reproductive condition in which the ovarian cycles do not start even 40 days after calving [33]. A persistent corpus luteum is defined as the reproductive condition in which functional corpora lutea are retained for a long period, causing the absence of estrus [24].

The survey period was 305 days, corresponding to one lactation period starting from the time of the last delivery for each cow. Blood samples were collected from the jugular veins of 60 cows (mild: 12, moderate: 20 and severe: 28 ) at the first examination and were evaluated for the blood urea nitrogen (BUN), aspartate transaminase (AST), alanine aminotransferase (ALT), alkaline phosphatase (ALP), $\gamma$-glutamyl transpeptidase ( $\gamma$-GTP), total bilirubin (T-Bil), glucose (Glu), triglyceride (TG), non-esterified fatty acids (NEFA), total cholesterol (T-Cho) and total protein (TP) levels. The samples were submitted to the Health Sciences Research Institute, Inc. (Yokohama, Japan) for the analysis of the blood chemistry.

The age, number of parities, body weight, interval between deliveries, postpartum day at the onset of ketosis, frequency of treatment, duration for cure and the results of the blood chemistry tests were compared among the three FL groups using a one-way analysis of variance and the TukeyKramer method.

The comparisons of the culling rates due to secondary diseases between the $\mathrm{C}$ and $\mathrm{NC}$ groups of the animals from the mild, moderate and severe FL groups were performed using the chi-square test. Additionally, the differences among the mild, moderate and severe FL groups in the total occurrence rates of five types of ovarian diseases and in the culling rates were analyzed using the $\chi^{2}$ test. The results are presented as the mean \pm standard error (SEM). The significance level was set at $5 \%$ or below.

\section{RESULTS}

There were no significant differences $(P<0.05)$ among the animals of the three FL groups in terms of the mean age, number of parities, body weight, interval between deliveries, postpartum day at the onset of ketosis, frequency of treatment and duration for cure (Table 1).

The blood chemistry findings of samples collected from 89 cows at the first examination for the diagnosis of FL are shown in Table 2. The mean NEFA level of the severe FL group $(1,428.5 \pm 108.7 \mu \mathrm{Eq} / l)$ was significantly higher $(P<0.05)$ than that of the mild FL group $(1,005.5$ $\pm 141.9 \mu \mathrm{Eq} / l)$ and the moderate FL group $(1,047.5 \pm$ $88.9 \mu \mathrm{Eq} / l)$. The mean Glu levels were significantly lower in the moderate $(50.2 \pm 3.5 \mathrm{mg} / \mathrm{d} l)$ and severe $(49.2 \pm 3.1 \mathrm{mg} /$ $\mathrm{d}$ ) FL groups, compared to those of the mild group (72.7 \pm $8.5 \mathrm{mg} / \mathrm{d} l)(P<0.01)$. No significant difference was noted in the results of any other parameter among the groups.

The incidence of death or culling due to the secondary diseases showed a significantly higher rate in the $\mathrm{C}$ group than it did in the NC group (Table 3). The culling rate among the cows with systemic diseases was significantly lower in the mild FL group, compared to that in the moderate $(P<0.05)$ and severe $(P<0.01)$ FL groups. No ovarian diseases were reported in the cows of the $\mathrm{C}$ group $(\mathrm{n}=126)$.

Of the 107 cows that had not developed any systemic diseases, 62 (78 episodes in total) developed ovarian disease. 
Table 2. Blood chemistry in three severity groups of fatty livers

\begin{tabular}{lccc}
\hline & Mild $(\mathrm{n}=12)$ & Moderate $(\mathrm{n}=20)$ & Severe $(\mathrm{n}=28)$ \\
\hline BUN $(\mathrm{mg} / \mathrm{d} l)$ & $13.5 \pm 2.1$ & $13.2 \pm 1.1$ & $13.1 \pm 0.6$ \\
AST $(\mathrm{IU} / l)$ & $114.3 \pm 12.3$ & $171.4 \pm 21.2$ & $135.5 \pm 21.4$ \\
ALT $(\mathrm{IU} / l)$ & $15.5 \pm 2.3$ & $20.2 \pm 3.4$ & $16.2 \pm 1.6$ \\
ALP $(\mathrm{U} / l)$ & $4.6 \pm 0.6$ & $5.1 \pm 0.6$ & $5.3 \pm 0.6$ \\
$\gamma$-GTP $(\mathrm{U} / l)$ & $28.8 \pm 3.6$ & $22.1 \pm 2.3$ & $50.0 \pm 13.5$ \\
T-Bili $(\mathrm{mg} / \mathrm{d} l)$ & $0.8 \pm 0.2$ & $0.8 \pm 0.1$ & $0.8 \pm 0.1$ \\
Glu $(\mathrm{mg} / \mathrm{d} l)$ & $\left.72.7 \pm 8.5^{\mathrm{A}}\right)$ & $\left.50.2 \pm 3.5^{\mathrm{B}}\right)$ & $\left.49.2 \pm 3.1^{\mathrm{B}}\right)$ \\
TG $(\mathrm{mg} / \mathrm{d} l)$ & $18.1 \pm 3.2$ & $18.8 \pm 1.3$ & $28.0 \pm 6.6$ \\
NEFA $(\mu \mathrm{Eq} / l)$ & $\left.1,005.5 \pm 141.9^{\mathrm{a}}\right)$ & $\left.1,047.5 \pm 88.9^{\mathrm{a}}\right)$ & $\left.1,428.5 \pm 108.7^{\mathrm{b}}\right)$ \\
T-Cho $(\mathrm{mg} / \mathrm{d} l)$ & $127.8 \pm 23.7$ & $89.1 \pm 8.1$ & $99.7 \pm 10.9$ \\
TP $(\mathrm{g} / \mathrm{m} l)$ & $8.3 \pm 0.4$ & $7.7 \pm 0.2$ & $7.7 \pm 0.2$ \\
\hline
\end{tabular}

Fatty liver has been categorized into three classes: a mild fatty liver (mild) with a fat deposition rate of $10-30 \%$; moderate fatty liver (moderate) with a fat deposition rate of $30-60 \%$; and severe fatty liver (severe) with a fat deposition rate of $60 \%$ or more. Values with different superscripts within each row differ significantly. Capital letters indicate statistical significance at $P<0.01$, and the small letters indicate statistical significance at $P<0.05$.

Table 3. Rate of culling and secondary ovarian diseases in the three groups of cows with fatty liver

\begin{tabular}{|c|c|c|c|c|}
\hline & & Mild $(n=99)$ & Moderate $(n=56)$ & Severe $(n=78)$ \\
\hline $\mathrm{C}$ group ${ }^{1)}$ & Rate of culling $(\%)^{3)}$ & $\left.53.1(26 / 49)^{* * a}\right)$ & $75.0(24 / 32)^{* * b)}$ & $\left.88.9(40 / 45)^{*} \mathrm{~b}\right)$ \\
\hline \multirow{7}{*}{ NC group ${ }^{2)}$} & Ovulation failure (\%) & $8.0(4 / 50)$ & $25.0(6 / 24)$ & $30.3(10 / 33)$ \\
\hline & Follicular cyst $(\%)$ & $6.0(3 / 50)$ & $25.0(6 / 24)$ & $27.3(9 / 33)$ \\
\hline & Subestrus (\%) & $14.0(7 / 50)$ & $12.5(3 / 24)$ & $21.2(7 / 33)$ \\
\hline & Ovarian quiescence $(\%)$ & $8.0(4 / 50)$ & $16.7(4 / 24)$ & $18.2(6 / 33)$ \\
\hline & Retained corpus luteum (\%) & $4.0(2 / 50)$ & $8.3(2 / 24)$ & $15.2(5 / 33)$ \\
\hline & Total ovarian diseases $(\%)$ & $40.0(20 / 50)^{\mathrm{a})}$ & $58.3(14 / 24)^{4)}$ a) & $84.9(28 / 33)^{5)}$ b) \\
\hline & Rate of culling (\%) & $10.0(5 / 50)^{\mathrm{a})}$ & $37.5(9 / 24)^{b)}$ & $69.7(23 / 33)^{\mathrm{c})}$ \\
\hline
\end{tabular}

Fatty liver has been categorized into three classes: a mild fatty liver (mild) with a fat deposition rate of $10-30 \%$; moderate fatty liver (moderate) with a fat deposition rate of 30-60\%; and severe fatty liver (severe) with a fat deposition rate of $60 \%$ or more. 1) The $\mathrm{C}$ group included the cows that developed secondary systemic diseases, such as liver disorders, mastitis, displacement of the abomasums and uterine diseases; 2) The $\mathrm{NC}$ group included the cows that did not develop systemic diseases; 3 ) Includes cases of death too; *and **: Asterisks indicate statistically significant differences between the rates of culling of groups $\mathrm{C}$ and $\mathrm{NC}(P<0.05$ and $P<0.01$, respectively); 4) Of the 14 cow (21 episodes in total) developed ovarian disease; 5) Of the 28 cow (37 episodes in total) developed ovarian disease; a, b, c) The rates with different superscripts in each row are significantly different $(P<0.05$ or $P<0.01)$.

When the secondary developments of the ovarian diseases were investigated in correlation with the liver fat deposition rate, it was found that the incidence rates of secondary ovarian disease were $40.0,58.3$ and $84.9 \%$, in the mild, moderate and severe FL groups, respectively (Table 3); the rate of incidence was significantly higher in the severe FL group than that in the mild $(P<0.01)$ and the moderate $(P<0.05)$ FL groups. The rates of incidence of ovulation failure were 8.0, 25.0 and $30.3 \%$ in the mild, moderate and severe FL groups, respectively; the rates of incidence of follicular cysts were $6.0,25.0$ and $27.3 \%$ in the mild, moderate and severe FL groups, respectively. The rates of incidence of subestrous (feeble internal estrus signs and unsuitability for artificial insemination) in the mild, moderate and severe FL groups were $14.0,12.5$ and $21.2 \%$, respectively; those of ovarian quiescence, $8.0,16.7$ and $18.2 \%$, respectively; and those of retained corpus luteum, $4.0,8.3$ and $15.2 \%$, respectively.
The culling rates among the cows with secondary ovarian diseases were $10.0,37.5$ and $69.7 \%$, in the mild, moderate and severe FL groups, respectively (Table 3); the rate was significantly higher in the severe FL group than those in the mild $(P<0.01)$ and the moderate $(P<0.05)$ FL groups, and it was significantly higher in the moderate FL group than that in the mild $\mathrm{FL}$ group $(P<0.01)$.

\section{DISCUSSION}

The liver biopsy of 366 cows diagnosed with ketosis after calving revealed that $>10 \%$ fat was deposited within the livers of more than half of the cows (233 cows, $63.7 \%$ ). The main symptoms of FL presented at the first examination were the presence of urinary ketone bodies and the loss or complete disappearance of appetite, along with dysstasia in many cases. These were similar to the symptoms reported 
by Morrow et al. in cows with FL [21]. The appearance of urinary acetone bodies in the early phase of lactation may have been due to the accumulation of triglycerides in the hepatocytes, resulting from an excess energy intake in the dry period and insufficient metabolic energy after delivery [27-29, 34].

Gaál and Husveth [8] and Gröhn et al. [11] stated that the most accurate method to diagnose the grade of fat deposition in the liver is liver biopsy. However, it is difficult to perform liver biopsy and to clearly distinguish between ketosis and FL at the clinical sites, and additionally, it was suggested that ketosis and FL developed simultaneously in many of the cases.

Reid and Robert [30] reported that changes in the blood chemistry, such as a decrease in the blood glucose level and an increase in the blood NEFA level, were noted in cows with the fat-cow syndrome accompanied by a FL, that had not yet developed clinical symptoms. In the present study, in the cows with a history of severe FL, the blood glucose levels were low and the blood NEFA levels were high, suggesting that the FL was correlated with the blood glucose and NEFA levels.

The death or culling rate was $18.0 \%(51 / 284)$ in the cows diagnosed with the initial stages of FL. The incidence of the secondary diseases in the surviving 233 cows was $80.7 \%$ $(188 / 233)$, the cure rate $32.4 \%(61 / 233)$ and the death or culling rate $67.6 \%(127 / 233)$, indicating a high incidence of secondary diseases and a high death or culling rate among the animals with FL. It may be assumed that once the cows develop a FL, some disorder remains even after the resolution of the clinical symptoms, resulting in an internal environment with reduced resistance to diseases and an impaired ability to utilize the ingested feed.

FL is accompanied by liver disorders and is closely involved in various productivity-related diseases [7, 12, 20]. It causes a reduction in the subsequent conception rate and prolongs the intervals between the deliveries, thus, markedly influencing the reproductive performance [28, 31, 32, 35]. Additionally, in the cows that had developed a FL, a decrease in the serum progesterone [42] and glucocorticoid [22] levels has been observed, suggesting that the reduction of cholesterol, which is a steroid hormone precursor, reduces the reproductive performance and immunity [9, 22]. Veenhuizen et al. [41] reported that the FL progresses to a severe grade before the symptoms of ketosis can appear and that the analysis of ketosis incidence in dairy cattle revealed that the UDP-glucuronosyltransferase (UGT) activity value of the liver is reduced in cases with FL. On the other hand, Ono et al. [23] reported that the progesterone and estrogen levels of the animals in estrus immediately after four days of fasting were significantly higher than those in the non-fasting group and that this elevation was attributed to a metabolic delay due to a reduction in liver blood flow. One of the features of the clinical symptoms in cases with moderate and severe FL is a decrease in the appetite [40], and it has been suggested that the reason for this could be the increase in the steroid hormone levels due to the reduced blood flow in a FL. Silvia et al. [37] reported that the occurrence of follicular cysts is due to the suppression of the surge in the luteinizing hormone (LH) concentrations produced in the hypothalamus when the progesterone concentration is between 0.1 and $1.0 \mathrm{ng} / \mathrm{m} l$. In the present study, it has been shown that the rates of the ovarian disease recurrence and the culling rates increased with an increase in the fat deposition rate in dairy cows with FL. This result suggests that the progression of the FL in cows results in the development of secondary ovarian diseases due to increased blood progesterone concentrations caused by a decreased blood flow and an increased UGT activity in the liver.

Several metabolic hormones are involved in perinatal nutritional control, of which the growth hormone $(\mathrm{GH})$ and insulin-like growth factor-1 (IGF-1) act as the main regulators. The GH is secreted by the anterior pituitary gland and is mainly involved in lactation control, reduction of insulin sensitivity, lipolysis and the promotion of the IGF-1 production in the liver in adult cows [43]. The IGF-1 is mainly produced in the liver, and, apart from the other tissues, its receptors are also present in the follicles and the corpus luteum $[16,43]$. The IGF-1 plays an important role in the follicular growth by increasing the sensitivity of the follicles to the follicle-stimulating hormone (FSH) and the $\mathrm{LH}$ and by acting on the LH receptors of the granular layer cells [16, 43]. The IGF-1 stimulates the proliferation of the granular cells of the follicles $[1,4,5,10]$ and stimulates steroid hormone production [38]. Additionally, it plays an important role in the regulation of the endocrine function, mediating the signals related to the changes in the nutritional condition to the gonads $[25,43]$. The IGF-1 has been reported to be an important factor related to the first ovulation after delivery; high blood IGF-1 and insulin levels stimulate the growth and the final maturation step of the dominant follicle in the first follicular wave after delivery [16]. Since the production and secretion of the IGF-1 occurs in the liver, the FL -associated liver hypofunction might have reduced the IGF-1 production and secretion and thus influenced the development of the ovarian diseases. In the present study, the incidence and severity of the ovarian diseases increased with an increase in the liver fat deposition rates, suggesting a close relationship between the liver function and the development of the ovarian diseases.

FL is usually diagnosed after the death or culling of the animal or after its death due to other diseases. Liver biopsy is the only direct and most reliable method to determine the severity of the FL in a living animal. Microscopic evaluation can be used to estimate the volume of the tissue occupied by fat. The liver fat content can then be used to identify the stage of the FL, which enables the distinction between several risk groups. The treatment of mild FL with injections of $5 \mathrm{mg}$ of glucagon every $8 \mathrm{hr}$ for 14 days might lead to fewer adverse effects on the health and reproduction in dairy cows [3]. Severe FL can be treated by consecutive intravenous injections of glucagon (10 mg/day) for 14 days [13]. Since severe FL requires more aggressive and long-term treatment, future research in this area will, hopefully, be able to provide novel treatment options, such as a slow-release formula of glucagon. 
It was concluded from the findings of our study that the death or culling rates and the ovarian disease recurrence rates increase with a corresponding increase in the fat deposition rates in dairy cows with FL and that cases with severe FL, with a fat deposition rate of $60 \%$ or higher, are associated with high rates of death or culling.

\section{REFERENCES}

1. Armstrong, D. G., Gong, J. G. and Webb, R. 2003. Interactions between nutrition and ovarian activity in cattle: physiological, cellular and molecular mechanisms. Reprod. Suppl. 61: 403-414. [Medline]

2. Bobe, G., Young, J. W. and Beitz, D. C. 2004. Invited review: pathology, etiology, prevention, and treatment of fatty liver in dairy cows. J. Dairy Sci. 87: 3105-3124. [Medline] [CrossRef]

3. Bobe, G., Ametaj, B. N., Young, J. W., Anderson, L. L. and Beitz, D. C. 2007. Exogenous glucagon effects on health and reproductive performance of lactating dairy cows with mild fatty liver. Anim. Reprod. Sci. 102: 194-207. [Medline] [CrossRef]

4. Butler, S. T., Pelton, S. H. and Bulter, W. R. 2004. Insulin increases 17 beta-estradiol production by the dominant follicle of the first postpartum follicle wave in dairy cows. Reproduction 127: 537-545. [Medline] [CrossRef]

5. Butler, S. T., Pelton, S. H. and Bulter, W. R. 2006. Energy balance, metabolic status, and the first postpartum ovarian follicle wave in cows administered propylene glycol. J. Dairy Sci. 89: 2938-2951. [Medline] [CrossRef]

6. Collins, R. A. and Reid, I. M. 1980. A correlated biochemical and stereological study of periparturient fatty liver in the dairy cow. Res. Vet. Sci. 28: 373-376. [Medline]

7. Coppock, C. E., Noller, C. H., Wolfe, S. A., Callahan, C. J. and Baker, J. S. 1972. Effect of forage concentrate ratio in complete feeds fed ad libitum on feed intake prepartum and the occurrence of abomasal displacement in dairy cows. J. Dairy Sci. 55: 783-789. [Medline] [CrossRef]

8. Gaál, T. and Husveth, F. 1983. Comparison of the liver biopsy sample and the "whole liver" in respect of lipid content and fatty acid composition of lipids. Acta Vet. Hung. 31: 51-56. [Medline]

9. Gerloff, B. J., Herdt, T. H. and Emery, R. S. 1986. Relationship of hepatic lipidosis to health and performance in dairy cattle. $J$. Am. Vet. Med. Assoc. 188: 845-850. [Medline]

10. Glister, C., Tannetta, D. S., Groome, N. P. and Knight, P. G. 2001. Interactions between follicle-stimulating hormone and growth factors in modulating secretion of steroids and inhibinrelated peptides by nonluteinized bovine granulose cells. Biol. Reprod. 65: 1020-1028. [Medline] [CrossRef]

11. Gröhn, Y., Lindberg, L. A., Bruss, M. L. and Farrer, T. B. 1983. Fatty infiltration of liver in spontaneously ketotic dairy cows. $J$. Dairy Sci. 66: 2320-2328. [Medline] [CrossRef]

12. Higgins, R. J. and Anderson, W. S. 1983. Fat cow syndrome in a British dairy head. Vet. Rec. 113: 461-463. [Medline] [CrossRef]

13. Hippen, A. R., She, P., Young, J. W., Beitz, D. C., Lindberg, G. L., Richardson, L. F. and Tucker, R. W. 1999. Alleviation of fatty liver in dairy cows with 14-day intravenous infusions of glucagon. J. Dairy Sci. 82: 1139-1152. [Medline] [CrossRef]

14. Jorritsma, R., Jorritsma, H., Schukken, Y. H. and Wentink, G. H. 2000. Relationships between fatty liver and fertility and some periparturient diseases in commercial Dutch dairy herds. Theriogenology 54: 1065-1074. [Medline] [CrossRef]

15. Katoh, N. 2002. Relevance of apolipoproteins in the development of fatty liver and fatty liver-related peripartum diseases in dairy cows. J. Vet. Med. Sci. 64: 293-307. [Medline] [CrossRef]

16. Kawashima, C., Fukihara, S., Maeda, M., Kaneko, E., Montoya, C. A., Matsui, M., Shimizu, T., Matsunaga, N., Kida, K., Miyake, Y., Schams, D. and Miyamoto, A. 2007. Relationship between metabolic hormones and ovulation of dominant follicle during the first follicular wave post-partum in high-producing dairy cows. Reproduction 133: 155-163. [Medline] [CrossRef]

17. Kesler, D. J. and Garverick, H. A. 1982. Ovarian cysts in dairy cattle: a review. J. Anim. Sci. 55: 1147-1159. [Medline]

18. Kimura, Y., Arai, K., Minato, K. and Noro, A. 1993. Changes in milk, blood and rumen components at each lactation stage of dairy cows with high milk production. J. Jpn. Vet. Med. Assoc. 46: 385-391 (in Japanese with English summary). [CrossRef]

19. Kobayashi, Y., Boyd, C. K., McCormack, B. L. and Lucy, M. C. 2002. Reduced insulin-like growth factor-I after acute feed restriction in lactating dairy cows is independent of changes in growth hormone receptor 1A mRNA. J. Dairy Sci. 85: 748-754. [Medline] [CrossRef]

20. McCormack, J. 1978. Fat-cow syndrome and its complications. Vet. Med. Small Anim. Clin. 73: 1057-1060. [Medline]

21. Morrow, D. A., Hillman, D., Dade, A. W. and Kitchen, H. 1979. Clinical investigation of a dairy herd with the fat cow syndrome. J. Am. Vet. Med. Assoc. 174: 161-167. [Medline]

22. Morrow, D. A. 1976. Fat cow syndrome. J. Dairy Sci. 59: 1625-1629. [Medline] [CrossRef]

23. Ono, M., Ohtaki, T., Tanemura, K., Ishii, M., Watanabe, G., Taya, K. and Tsumagari, S. 2011. Effect of short-term fasting on hepatic steroid hormone metabolism in cows. J. Vet. Med. Sci. 73: 1145-1149. [Medline] [CrossRef]

24. Parkinson, T. 2009. Infertility and subfertility in the cow: structural and functional abnormalities, management deficiencies and non-specific infections. pp. 393-475. In: Veterinary Reproduction and Obstetrics, 9th ed. (Noakes, D. E., Parkinson, T. J. and England, G. C. W. eds.), Elsevier, Amsterdam.

25. Patton, J., Kenny, D. A., McNamara, S., Mee, J. F., O’Mara, F. P., Diskin, M. G. and Murphy, J. J. 2007. Relationships among milk production, energy balance, plasma analytes, and reproduction in Holstein-Friesian cows. J. Dairy Sci. 90: 649-658. [Medline] [CrossRef]

26. Radcliff, R. P., McCormack, B. L., Keisler, D. H., Crooker, B. A. and Lucy, M. C. 2006. Partial feed restriction decrease growth hormone receptor 1A mRNA expression in postpartum dairy cows. J. Dairy Sci. 89: 611-619. [Medline] [CrossRef]

27. Reid, I. M. 1980. Incidence and severity of fatty liver in dairy cows. Vet. Rec. 107: 281-284. [Medline] [CrossRef]

28. Reid, I. M., Dew, S. M., Collins, R. A., Ducker, M. J., Bloomfield, G. A. and Morant, S. V. 1983. The relationship between fatty liver and fertility in dairy cows: a farm investigation. $J$. Agric. Sci. 101: 499-502. [CrossRef]

29. Reid, I. and Robert, C. J. 1982. Fatty liver in dairy cows. In Pract. 4: 164-169. [Medline] [CrossRef]

30. Reid, I. M. and Robert, C. J. 1983. Subclinical fatty liver in dairy cows. Current research and future prospects. Ir. Vet. J. 37: 104-110.

31. Reid, I. M., Robert, C. J. and Manston, R. 1979. Fatty liver and infertility in high-yielding dairy cows. Vet. Rec. 104: 75-76. [Medline] [CrossRef]

32. Reid, I. M., Robert, C. J. and Manston, R. 1979. Reduced fertility associated with fatty liver in high-yielding dairy cows. Vet. Sci. Commun. 3: 231-236. [CrossRef]

33. Robert, S. J. 1986. Infertility in the cow. pp. 495-512. In: Veterinary Obstetrics and Genital Disease (Theriogenology) 3rd ed., Edwards Brothers Inc., Ann Arbor. 
34. Roberts, C. J., Reid, I. M., Rowlands, G. J. and Patterson, A. 1981. A fat mobilization syndrome in dairy cows in early lactation. Vet. Rec. 108: 7-9. [Medline] [CrossRef]

35. Rowlands, G. J., Little, W. and Kitchenham, B. A. 1977. Relationships between blood composition and fertility in dairy cows: a field study. J. Dairy Res. 44: 1-7. [Medline] [CrossRef]

36. Sato, S., Ono, H., Uematu, M., Hatakeyama, N. and Tunoda, M. 2003. Blood components of periparturient diseased cows during dry periods. Jpn. J. Large Anim. Clin. 26: 21-26 (in Japanese with English summary).

37. Silvia, W. J., Hatler, T. B., Nugent, A. M. and Laranja da Fonseca, L. F. 2002. Ovarian follicular cysts in dairy cows: an abnormality in folliculogenesis. Domest. Anim. Endocrinol. 23: 167-177. [Medline] [CrossRef]

38. Spicer, L. J., Alpizar, E. and Echternkamp, S. E. 1993. Effects of insulin, insulin-like growth factorI, and gonadotropins on bovine granulosa cell proliferation, progesterone production, estradiol production, and (or) insulin-like growth factor in vitro. J. Anim. Sci. 71: 1232-1241. [Medline]

39. Tamura, T., Seimiya, Y., Takahashi, M. and Murakami, R. 2003.
Hepatic encephalopathy associated with severe fatty liver in a post-parturient cow. J. Jpn. Vet. Med. Assoc. 56: 587-591 (in Japanese with English summary). [CrossRef]

40. Tanemura, K., Ohba, S., Hirai, S., Nishiyama, A., Tsumagari, S. and Takeishi, M. 1986. Therapeutic effect of Thiopronine on bovine fatty liver. J. Jpn. Vet. Med. Assoc. 39: 749-756 (in Japanese with English summary). [CrossRef]

41. Veenhuizen, J. J., Drackley, J. K., Richard, M. J., Sanderson, T. P., Miller, L. D. and Young, J. W. 1991. Metabolic changes in blood and liver during development and early treatment of experimental fatty liver and ketosis in cows. J. Dairy Sci. 74: 4238-4253. [Medline] [CrossRef]

42. Watson, E. D. and Williams, L. A. 1987. Influence of liver fat on post-partum hormone profiles in dairy cows. Anim. Prod. 45: 9-14. [CrossRef]

43. Zulu, V. C., Nakao, T. and Sawamukai, Y. 2002. Insulin-like growth factor-I as a possible hormonal mediator of nutritional regulation of reproduction in cattle. J. Vet. Med. Sci. 64: 657665. [Medline] [CrossRef] 